\title{
Empirical Investigation into Compensation Preferences for Diversified Employees
}

\author{
Ahmed Al-Asfour \\ Oglala Lakota College \\ Accepted: August 05, 2012 Published: September 22, 2012 \\ Doi:10.5296/ijhrs.v2i4.2587 \\ URL: http://dx.doi.org/10.5296/ijhrs.v2i4.2587
}

\begin{abstract}
Motivational factors play an essential role with increasing employee job satisfaction. Satisfied employees in return can help improve organizational performance. Hence, it is the purpose of this paper to examine intrinsic and extrinsic motivation preferences between domestic and foreign employees working at a factory in the Kingdom of Saudi Arabia. Three hypotheses were developed and examined by the researcher. The first and second tests showed that foreign and domestic employees view both intrinsic and extrinsic motivation alike. The third hypothesis stated that the employees would prefer one motivation method, and indeed the t-test showed that employees rated extrinsic motivation more highly than intrinsic
\end{abstract}

Keywords: Domestic \& Foreign Employees Motivation, Intrinsic \& Extrinsic Employees Motivation, Reward Systems

\section{INTRODUCTION}

The effectiveness of any organization is greatly influenced by human behavior. Effective administrative help creates a work environment that encourages productivity and innovation in employee work motivation. Because of this, organizations use reward systems to channel motivation in desired ways. In different terms, reward systems attempt to attract skillful employees to join or continue working for an organization. Reward systems influence all employees of an organization regardless of its size and place. Although the methods of motivation and compensation may differ between occupations, organizations none the less, attempt to motivate all employees. The level of motivation may vary based on the type of organization and its needs.

Every organization and business wants to be successful and has a desire to get a constant level of employee performance. The current era of conducting a business is highly competitive. Organizations utilize all means available to compete with the best technology, products, and most importantly workforce obtainable in the market. Hongping (2006) stated that the performance quality of the employees correlates with motivation. Because employees 
are motivated differently, this research aims to investigate the preferences of rewards offered by a business organization in the Kingdom of Saudi Arabia (KSA). This organization is located in the eastern province of the KSA and employs a diverse workforce. The majority of employees are expatriates working and living in the Kingdom.

\section{Study Rational}

For the past several decades, there have been a growing number of expatriates entering the job market in the KSA. This is due in part to the discovery of oil, which has created millions of jobs for foreign workers from different parts of the world. In the KSA, there are millions of expatriates from India, Pakistan, Philippines, United Kingdom, United States, and several other countries. Some of these employees are skilled, some are unskilled, and they come from individualistic and collectivistic cultures. The issue of workforce diversity has become increasingly important to understand in the last few years for managers, supervisors, and consultants to realize the composition of the workforce effects on organizational productivity (Griffin \& Mooread, 2010). Money and many other forms of rewards have been used to motivate, attract, and retain employees to achieve organizational goals. Terry (2006) pointed out that understanding what motivates a multicultural workforce is important. In addition, due to the limited research on multicultural motivation factors, this research attempted to examine the differences of reward needs between employees. The objectives of the research are summarized in the following:

1. To determine the impact of intrinsic motivation on both domestic (Saudi citizens) and foreign employees;

2. To determine the impact of extrinsic motivation on both domestic (Saudi citizens) and foreign employees; and

3. To examine differences in employee preferences between intrinsic and extrinsic motivational methods.

\section{LITERATURE REVIEW}

The literature review focused on what motivates employees. Owners of businesses and managers who seek the answers to motivation may look into theories for support. The word motivate is "something that causes a person to act in a certain way, do a certain thing, etc; incentive" (Dictionary.com). Motivation means achieving results through people or getting the best potential out of people. Motivation is a power that should strengthen behavior, give route to behavior, and trigger the tendency to continue their work (Everard \& Morris, 1996).

Maslow (1970) is one of the well-known contributors to motivation needs theories. Maslow examined human needs and divided it into five levels. These needs are arranged in the form of a pyramid with physiological needs at the bottom. The second level is safety needs, which includes security of oneself and family. The third is the sense of belongingness and love by family, friends, and community. The fourth need is self-esteem, prestige, feeling of accomplishment, and respect. The final level in the pyramid is self-actualization. In this final stage, a person receives the highest accomplishment in the need hierarchy developed by Maslow.

Even though Maslow's theory of human needs have been widely accepted by many educators and other professionals, different scholars have come forth with their own theories. Two of these well-known scholars and theories were Alderfer with ERG Theory and 
McClelland's Acquired Needs Theory. According to Certo and Certo (2009), Alderfer's theory was to respond to "some of the criticism of Maslow's work by conducting his own study of human needs" (p.405). Aldefer identified three basic categories of needs:

1. Existence need-the need for physical well-being.

2. Relatedness need-the need for satisfying interpersonal relationships.

3. Growth need-the need for continuing personal growth and development.

McClelland's Acquired Needs Theory came up with his own theory of needs. According to Certo and Certo (2009) this theory, "formulated by David C. McClelland in the 1960 s, emphasizes three of the many needs human beings develop in their lifetimes" (p.406). These three needs are:

1. Need for achievement-the desire to do something better or more efficiently.

2. Need for power-the desire to control, influence, or be responsible for others.

3. Need for affiliation-the desire to maintain close, friendly, personal relationships with those who are cherished by us.

Organizations reward their employees in two ways-intrinsic and extrinsic. Buch and Tolentino (2006) defined intrinsic rewards as "are those that an individual receives internally as a result of their involvement in activities that enhances feelings of self competence, growth, satisfaction, responsibility and autonomy"(p.358). In addition, Buch and Tolentino defined extrinsic rewards as "those that employees receive from their organization or management as a result of their performance or participation" (p.357). Certo and Certo (2009) discussed that an intrinsic reward comes directly from performing the task, while an extrinsic reward is extraneous to the task. Griffin and Mooread (2010) explained Herzberg's view of motivation. Based on Herzberg's view of what motivates employees, motivation factors that represent intrinsic are examples of work itself, which includes factors such as achievement and recognition. In the meantime, hygiene factors represent extrinsic, which refers to factors such as pay and job security.

Vroom (1964) supported the assumption that employees tend to perform more effectively when their wages are related to performance. In addition, Vroom suggested that people are motivated by how much they want something and the likelihood they perceive of getting it, which Vroom referred to as the expectancy theory. In addition, French (2007) added that properly planned, installed, and administrated incentive plans can increase efficiency and productivity, decreases costs, and increase the pay of employees, supervisors, and managers. Pratheepkanth (2011) found a positive relationship between extrinsic rewards and employee motivation when extrinsic rewards are made on the desire of employees' needs. Furthermore, Pratheepkanth found that when employee needs are fulfilled through reward systems, employee consistency increases accordingly. Chiu and Luk (2002) mentioned that generous rewards tend to retain people because high reward levels lead to high satisfaction, commitment, and loyalty. Nelson and Spitzer (2003) found that using positive reinforcement incentives helped increase the performance level of employees and were the catalysts for improving employee productivity. Grensing-Pophal (2006) concluded that decisions related to how to keep employees satisfied, motivated, and productive are critical to the employees' overall performance. 
Conceptual Frame work

2012, Vol. 2, No. 4

Subsequent to a careful study of literature review on motivation theories and research, the following model was formulated to describe the aimed purpose of the study.

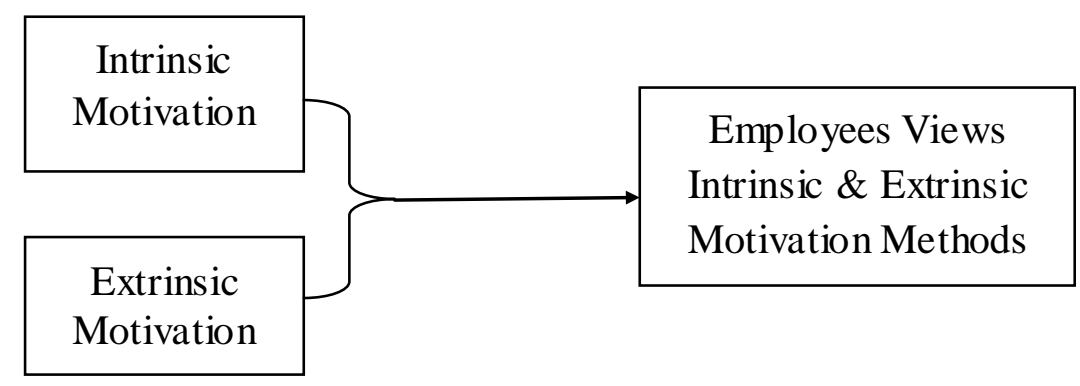

\section{Hypotheses}

Based on the literature and the model study designed, the following null hypotheses were developed:

- $\mathrm{H}_{1}$ : There is no difference between domestic and foreign employees' views on intrinsic motivation.

- $\mathrm{H}_{2}$ : There is no difference between domestic and foreign employees' views on extrinsic motivation.

- $\mathrm{H}_{3}$ : There is no significant difference in preferences between intrinsic and extrinsic motivation factors viewed by all employees.

\section{METHODS}

\section{Participants and Procedure}

The targeted population of this study was employees working at a furniture factory in the Kingdom of Saudi Arabia in the Eastern Province, which is in the eastern part of Saudi Arabia. The sample size included 96 employees from several countries working in Saudi Arabia. The total number of employees working at this factory was 250 employees. Hence, the sample collected consists of $38 \%$ of the available population.

The researcher sent a letter to the factory to solicit the participation in this study. After receiving permission from the factory management, the survey was e-mailed. The management asked the employees to voluntarily participate in this study. Due to language barriers, some employees needed translation of the survey from English to their own native language. The management accommodated the request by these employees. When the participants finished answering the survey questions, the answers were scanned and e-mailed to the researcher.

The participants in this study chose agree or disagree on a Likert-scale of one to five with five being strongly agree and one being strongly disagree. The completion of the survey was anonymous to the researcher. Face content validity for the instrument was established by using the factory management. The survey questions were pilot tested with ten employees and minor changes in word selection and instruction were made to the survey to ensure content validity. 


\section{Data Analysis}

The researcher used IBM SPSS to analyze the data. The statistical tests used for analysis were independent samples and paired samples t-test. There are three tables discussed in this study. The first one looks at the first hypothesis with an independent sample t-test, which is to examine if there is a difference between domestic and foreign employees on intrinsic motivation. The second table examines the second hypothesis by testing if there is a difference between domestic and foreign employees on extrinsic motivation. This also used an independent sample t-test. The third and final table looks into the third hypothesis to examine if there is a difference between intrinsic and extrinsic preference by employees with a paired-sample t-test

\section{RESULTS}

Using the data collected from the factory in Saudi Arabia, this section is designed to test the three hypotheses.

$\mathrm{H}_{1}$ : There is no difference between domestic and foreign employees' views on intrinsic motivation.

Table 1

View of Intrinsic Motivation

\begin{tabular}{lllllll}
\hline & $\mathrm{N}$ & $\mathrm{M}$ & $\mathrm{SD}$ & $t$ & $d f$ & $p$-value \\
\hline & & & & & & \\
Domestic Employees & 36 & 4.39 & 0.34 & .93 & 94 & .35 \\
Foreign Employees & 60 & 4.30 & 0.49 & & & \\
\hline
\end{tabular}

An independent sample t-test was conducted to compare intrinsic motivation between domestic and foreign employees. There was no significant difference between domestic $(\mathrm{M}=4.39, \mathrm{SD}=0.34)$ and foreign employees $(\mathrm{M}=4.30, \mathrm{SD}=0.49)$ based on intrinsic motivation $\mathrm{t}=.93, \mathrm{p}=.35$, and the degree of freedom $(\mathrm{df}=94)$. Hence, the researcher accepted the first null hypothesis that there is no difference between employees in the factor of intrinsic motivation.

$\mathrm{H}_{2}$ : There is no difference between domestic and foreign employees' views on extrinsic motivation.

Table 2

View of Extrinsic Motivation

\begin{tabular}{lllllll}
\hline & $\mathrm{N}$ & $\mathrm{M}$ & $\mathrm{SD}$ & $t$ & $d f$ & p-value \\
\hline & & & & & & \\
Domestic Employees & 36 & 4.54 & 0.35 & 1.41 & 94 & .16 \\
Foreign Employees & 60 & 4.42 & 0.43 & & & \\
\hline
\end{tabular}

An independent sample t-test was conducted to compare extrinsic motivation between domestic and foreign employees. There was no significant difference between domestic employees $(\mathrm{M}=4.54, \mathrm{SD}=.35)$ and foreign employees $(\mathrm{M}=4.42, \mathrm{SD}=.43)$ based on extrinsic motivation, $\mathrm{t}=1.41, \mathrm{p}=0.16$, and $\mathrm{df}=94$. Hence, the researcher accepted the second null hypothesis that there is no difference between employees in the factor of extrinsic motivation.

$\mathrm{H}_{3}$ : There is no significant difference in preferences between intrinsic and extrinsic motivation factors viewed by all employees. 
Table 3

View of Intrinsic and Extrinsic Motivation

\begin{tabular}{lcccccc}
\hline & $\mathrm{N}$ & $\mathrm{M}$ & $\mathrm{SD}$ & $t$ & $d f$ & p-value \\
\hline Intrinsic Motivation & 96 & 4.36 & 0.44 & -2.57 & 95 & .010 \\
Extrinsic Motivation & 96 & 4.46 & 0.40 & & & \\
\hline
\end{tabular}

Paired sample t-test was conducted to compare intrinsic and extrinsic motivation. When the researcher compared both intrinsic and extrinsic motivation, employees showed significant difference between the two, with intrinsic $(\mathrm{M}=4.36, \mathrm{SD}=0.44)$ and extrinsic $(\mathrm{M}=4.46, \mathrm{SD}=0.40)$, intrinsic vs. extrinsic motivation, $\mathrm{t}=-2.57, \mathrm{p}=.010$, and $\mathrm{df}=95$. Hence, there was a statistical significance and the researcher rejected the third null hypothesis that intrinsic and extrinsic motivational methods are preferred the same by employees regardless of the country of citizenship. In fact, employees preferred extrinsic motivation over intrinsic as shown in table 3.

\section{DISCUSSION}

The primary focus of this study was examining the three hypotheses presented in tables 1, 2, and 3. In the first two null hypotheses that were tested in this study, the researcher found no statistical significance. The third null hypothesis was rejected as the p-value was less than 0.05. It can be concluded from this study the following: (a) there is no difference between domestic and foreign employees' views on intrinsic motivation, (b) there is no difference between domestic and foreign employees' views on extrinsic motivation, and (c) there is significant difference in preferences between intrinsic and extrinsic rewards when compared simultaneously with each other.

The intrinsic motivational factors measured in the study included: verbal appreciation, public acknowledgement, professional growth, and opportunity for advancement. On the other hand, the extrinsic motivational factors measured in the study included: Money, gifts, health care benefits, vacation allowances, and school allowances for dependents. Rewards are the most common practices that management uses to acknowledge and compensate. Intrinsic rewards refer to the identification of appreciative work done by employees through verbal acknowledgment. In contrast, extrinsic rewards refer to the financial inducements that organizations offer to their employees for contributing to superior work.

While this study looked into intrinsic and extrinsic motivation factors, one cannot assume that there is a magic wand valid to motivate employees in every situation. Employees differ in their needs based on many factors such as demographics, social status, and others. The answer on how to motivate employees depends more on employees and their employers' ability to tap into employee inner desires and needs. It can be stated that the findings obtained from this study gave a fresh perspective into intrinsic and extrinsic motivation factors in one country that has employees from various backgrounds.

\section{Limitations}

The researcher was able to identify three limitations of this study. The first one is that the study was conducted at one factory in one location in Saudi Arabia. The second limitation was that a larger sample of participants is needed in order to have a better understanding of 
employee motivation preferences. The third and final limitation of the study is that no females were surveyed in this study. This was not intentional on the part of the researcher, but due to the labor law of Saudi Arabia. Males and females are not allowed to mingle in the workplace in the Kingdom except in hospitals and a very limited number of other occupations that are heavily monitored by the government.

\section{Conclusion and Further Research}

The study was conducted to test intrinsic and extrinsic motivation preferences for a multicultural workforce factory in the Kingdom of Saudi Arabia. The study concluded that there are no statistical significant differences in relationship between intrinsic and extrinsic preferences by employees. This is an important study on motivation examining both intrinsic and extrinsic factors in the context of multicultural workforce organizations. This study contributes to the understanding of many organizations operating within a globalized industry. This investigation also provides literature for future research on this topic of employees' motivation.

This is an important study on studying motivational methods for employees working in Saudi Arabia. Due to the rarity of research in this area, this research paper contributes to this kind of growing area of literature in motivation. This study also provides literature for future researchers to build on studying workforce motivation in multicultural environments. Hence, the researcher recommends future studies in various forms of organizations. In addition, future studies should look into conducting studies in neighboring countries of Saudi Arabia such as Bahrain and Kuwait where females have more autonomy and more diversity exists in the workplace. 
References

Buch, K., \& Tolentino, A. (2006). Employee perceptions of the rewards associated with six sigma. Journal of Organizational Change Management, 19(3), 356-364.doi: $10.1108 / 09534810610668355$.

Certo, S.C., \& Certo, S. T. (2009). Modern management. (11ed.).Upper Saddle River, New Jersey: Pearson.

Chiu,R.K.,\& Luk,V.W (2002). Retaining and motivating employees: Compensation preferences in Hone Kong and China. Personal review, 31(4), 402-431.doi 10.1108/00483480210430346.

Everard, K.B. \& Morris, G. (1996). Effective School Management (3rd ed). London: Paul Chaman.

French, W. (2011). Human resources management (6 ed.). Boston, MA: Houghton Mifflin.

Grensing-Pophal, L. (2006). Compensation philosophies. Credit Union Management, 29(9), 42-46.

Griffin, R., \& Moorhead, G. (2010). Organizational behavior: Managing people and organizations. (10 ed.). Manson, $\mathrm{OH}$ : Cengage Learning.

Maslow, A. (1970). Motivation and personality. New York: Harper\& Row.

Nelson, B., \& Spitzer, D. (2003). The money motivation myth. Leadership Excellence, 20(12), 18-18.

Partheepkanth, P (2011). Reward system and its impact on employee motivation in commercial bank of sri lanka plx, in jaffna distric. Global Journal of Management and Business Research, XI (IV), 84-92.

Terry, J (2007). Motivating a multicultural work force. Emerald Group Publishing Limited, 39(1), 1-59. doi: 10.1108/00197850710721417.

Vroom, V. (1964). Work and motivation. New York: Wiley. 